\title{
PRÁTICAS PEDAGÓGICAS INTEGRADORAS NO ENSINO MÉDIO INTEGRADO
}

\author{
F. A. A. SANTOS ${ }^{1,{ }^{*}}$, J. D. SANTOS ${ }^{2}$, V. P. PROFESSOR ${ }^{3}$, A. R. SILVA ${ }^{4}$ \\ 1,2,3,4 Instituto Federal de Educação, Ciência e Tecnologia do Rio Grande do Norte \\ alexandre.araujo@ifrn.edu.br
}

Submetido 17/08/2018 - Aceito 08/11/2018

DOI: $10.15628 /$ holos.2018.7611

\section{RESUMO}

Nesse artigo objetivamos fazer um estudo acerca das práticas pedagógicas integradoras utilizadas pelos professores do Ensino Médio Integrado (doravante EMI). $O$ estudo trata de um estado do conhecimento realizado por meio do banco de dados Google Acadêmico em um recorte temporal de 2007 a 2017. As análises desse trabalho partem de quatorze textos que apresentam em sua temática práticas educativas que auxiliem na implementação do currículo integrado e possam assim contribuir para a formação dos sujeitos envolvidos no processo de ensino-aprendizagem. Dentre essas práticas educativas integradoras, vê-se que, comumente ocorrem aquelas que partem da articulação de projetos interdisciplinares e de projetos integradores. O estudo evidencia a necessidade de práticas integradoras no EMI pela relevância de sua aproximação entre teoria e prática na integração das disciplinas e áreas do conhecimento, assim como pela sua efetiva contribuição na consolidação de um currículo integrado.

PALAVRAS-CHAVE: práticas integradoras, ensino médio integrado, integração curricular.

\section{INTEGRATED PEDAGOGICAL PRACTICES IN INTEGRATED HIGH SCHOOL}

\begin{abstract}
In this article we aim to make a study about integrative pedagogical practices used by teachers of the Integrated High School (hereinafter EMI). The study deals with a state of knowledge made through the Google Academic database, in a temporal cut from 2007 to 2017. The analyzes of this work start from fourteen texts that present in their theme educational practices that help in the implementation of the integrated curriculum and can contribute to the training of the subjects involved in
\end{abstract}

the teaching-learning process. Among these integrative educational practices, we can see that, usually, those that start from the articulation of interdisciplinary projects and integrative projects. The study evidences the need for integrative practices in EMI due to the relevance of its approximation between theory and practice in the integration of disciplines and areas of knowledge, as well as its effective contribution in the consolidation of an integrated curriculum.

KEYWORDS: integrative practices, integrated high school, curricular integration. 


\section{INTRODUÇÃO}

Este trabalho partiu das discussões realizadas durante o desenvolvimento da disciplina Práticas Educativas em EPT, do mestrado Profissional em Educação Profissional e Tecnológica ProfEPT no polo Mossoró - IFRN, no qual foi solicitado como requisito avaliativo, a elaboração de um artigo resultante de uma pesquisa realizada na perspectiva do Estado do Conhecimento sobre as Práticas Pedagógicas Integradoras no contexto do Ensino Médio Integrado - EMI.

As práticas integradoras ocorrem principalmente no âmbito do Ensino Médio Integrado. Este por sua vez, tem sua origem com a aprovação do decreto 5.154/2004, sendo considerado uma conquista para aqueles que defendem a união da educação básica com a educação profissional, marcada historicamente pela dualidade entre formação geral e formação técnica, pela fragmentação do ensino e formação desigual entre "elites" e classes trabalhadoras.

Dentre os objetivos do EMI, têm-se a formação integral/omnilateral, a formação politécnica e a integração das disciplinas propedêuticas e técnicas sob os eixos das categorias do trabalho, da ciência, da cultura e da tecnologia fundamentados no currículo integrado (RAMOS, 2005 apud FRIGOTTO; CIAVATTA, 2005). O currículo integrado propõe uma ruptura com a lógica disciplinar e tem como fio condutor, a interdisciplinaridade como mediadora da integração entre os saberes gerais e específicos, abrangendo o conhecimento com uma totalidade.

Para a construção do currículo integrado, faz-se necessária a reflexão, a análise da prática pedagógica e a mudança de postura por parte das instituições ofertantes, dos gestores, estudantes e educadores, os quais acostumados com práticas educativas já enraizadas, às quais levam à fragmentação do conhecimento, encontram dificuldades para implementá-lo. No entanto, embora em números menos expressivos, existem pesquisas que demostram experiências com práticas pedagógicas exitosas que caminham para a integração curricular e formação integrada dos estudantes. Acreditamos ser de suma relevância, investigações científicas a respeito destas experiências que poderão incitar outras instituições a desenvolvê-las.

Desta forma, este artigo tem como objetivo investigar as práticas pedagógicas integradoras utilizadas no Ensino Médio Integrado a partir do estado do conhecimento utilizando o banco de dados do google acadêmico no período de 2007 a 2017. A pergunta de pesquisa norteadora foi a seguinte: De que maneira se configura o panorama das práticas integradoras no contexto do Ensino Médio Integrado, a partir de uma investigação por meio do estado do conhecimento, utilizando-nos do banco de dados google acadêmico no período de 2007 a 2017 ? Para tanto, a primeira seção destina-se a um aprofundamento teórico sobre práticas educativas, tendo Zabala (1998), Libâneo (2013), Sacristán e Gomez (2009) como aporte teórico, além de trazer considerações sobre algumas das práticas pedagógicas integradoras, evidenciando suas contribuições para a integração de conhecimentos e, consequentemente, para a efetivação do currículo integrado e alcance dos objetivos do $\mathrm{EMI}$, os quais requerem tomada de atitude e compromisso com a transformação do ensino. Na segunda seção far-se-á um mapeamento das pesquisas sobre práticas pedagógicas integradoras que nos possibilitará uma visão geral das produções nesta área e, por fim, teceremos algumas considerações a partir da reflexões desencadeadas durante as análises das referidas produções. 


\section{PRÁTICAS EDUCATIVAS E PRÁTICAS INTEGRADORAS}

Em sentido estrito, a prática educativa ocorre em instituições de ensino de forma consciente, planejada e intencional sem se separar do processo mais global, abrangendo diversas complexidades imanentes à vida em sociedade (LIBÂNEO, 2013.) Contudo, faz-se mister enfatizar que as práticas educativas abordadas nesta pesquisa restringem-se àquelas que ocorrem de forma sistematizada nas escolas.

Por ter intencionalidade, a prática educativa deve ter objetivos definidos conscientemente, levando em consideração: métodos, técnicas, lugares e condições prévias específicas para alcançar os fins almejados. Tal sistematização não deve ser organizada de forma simplista, técnica ou metodológica, parcelando a realidade e estudando-a em separado, isto é, tratando como fragmentado aquilo que na prática educativa deveria ser realizado em conjunto, sob uma perspectiva positivista. As variáveis que configuram a prática educativa perdem sentido se não tiverem uma concepção unitária do processo de ensino-aprendizagem.

Consoante Libâneo (2013), a prática educativa consiste em um "fenômeno social e universal" que integra a natureza humana e se mostra necessária para a existência e funcionamento da sociedade. Assim, o trabalho educativo faz parte de um processo formativo mais amplo em que todos os sujeitos estejam preparados para a participação na vida social.

As variáveis que interferem no contexto da prática educativa, em geral, são elementos essenciais para compreender que a prática docente possui, respectivamente, um antes e depois da execução, ou seja, o planejamento e a avaliação, que se constituem em variáveis que, embora, ocorram em momentos distintos, elas deverão ser definidas, a priori (SACRISTÁN; GOMES, 2009).

Por sua vez, as atividades ou tarefas possuem em seu conjunto, todas as variáveis que incidem neste processo, mas, se trabalhadas de maneira isolada, se tornam limitadas. As outras variáveis também são de grande importância, dentre elas, estão: o papel dos professores e dos alunos; a forma de o professor interagir com os diferentes alunos; a utilização dos espaços e do tempo; a maneira de organizar os conteúdos; a existência, as características e o uso dos materiais curriculares e outros recursos didáticos e o sentido e o papel da avaliação.

Por sua vez, a sequência didática, é a unidade preferencial de análise, pois, permite o estudo e a avaliação sobre uma perspectiva processual que inclua as fases de planejamento, aplicação e avaliação, tal como a visão de totalidade da prática educativa, em que todas as suas partes estão estreitamente ligados (ZABALA, 1998).

Ainda, é de suma importância, a compreensão da função social do ensino e alguns questionamentos, tais como: para que educar? para que ensinar? tendo em vista que os fins e os propósitos sobre a educação influirão no que se ensina, inclusive, os conhecimentos e as disciplinas escolares. Assim, deve-se contextualizar a prática social e politicamente (LIBÂNEO, 2013), levando-se em conta as aprendizagens dos educandos, bem como as características sociais e os objetivos da prática educativa, dentre outros como afirma Zabala (1998) ao observar a estreita inter-relação entre as fontes didática e psicológica.

Tais aportes oferecem-nos condições de idealizar práticas a partir de determinados modelos teóricos, entretanto, observando a complexidade da prática educativa. Cabe frisar que é 
importante adequar as práticas de acordo com os condicionantes do contexto educativo, observando os que impedem, dificultam ou delimitam o desenvolvimento integral dos estudantes (SACRISTÁN; GOMES, 2009).

Ao observar as práticas educativas e as variáveis que influem no ensino médio integrado, percebemos que elas possuem particularidades, principalmente, se considerarmos sua função social de natureza abrangente e com o fito de desenvolver em suas práticas pedagógicas, as múltiplas perspectivas, a prática de um currículo integrado objetivado para formar um cidadão crítico, ativo, criativo e não somente um técnico, isto é, preconiza a formação integral.

Essas características fazem com que o currículo disciplinar não atenda aos requisitos de uma formação que se configure como integral e de natureza integrada, uma vez que, um ensino fragmentado não abrange o conhecimento como uma totalidade, tampouco, atenta para o contexto educacional, às expectativas e necessidades dos educandos ao longo de sua formação.

Diante do exposto, advém como proposta, o currículo integrado que tem como premissas a união entre teoria e prática e a indissociabilidade entre saberes gerais e específicos na perspectiva da construção do conhecimento como uma totalidade. Para que isso aconteça é indispensável que a interdisciplinaridade esteja presente na prática educativa, possibilitando um diálogo entre as disciplinas, por exemplo, propedêuticas e técnicas, em uma perspectiva de formação integral. Neste contexto, as práticas integradoras que sejam embasadas no currículo integrado constituem-se em um grande desafio e

[...]demandam maior estudo porque ultrapassa as noções de união, justaposição, relação e articulação entre saberes. A ideia-ação da integração não admite a fragmentação e o distanciamento entre áreas de conhecimento, ainda que, aparentemente, sejam paradoxais (HENRIQUE e NASCIMENTO, 2015, p. 75).

Diante disso, surgem propostas que em seus fundamentos metodológicos cumprem ou podem cumprir esta visão. A mais ampla e evidente prática educativa nesta categoria é a de natureza integradora. Essas práticas com fundamentos interdisciplinares e embasadas no currículo integrado buscam produzir os conhecimentos almejados no currículo integrado, sendo elas, a formação omnilateral, politécnica e o trabalho como princípio educativo, por meio da articulação entre teoria e prática, o que não significa apenas distribuir disciplinas técnicas e propedêuticas no currículo. As escolhas destas práticas não devem ser neutras, mas embasadas na concepção de um projeto de transformação social, na busca de emancipação e autonomia dos estudantes para que sejam capazes de refletir criticamente e intervir na realidade social e política.

Quanto a forma de realização das práticas integradoras, não existem fórmulas prontas, nem um único método, assim, a maioria das variáveis podem ocorrer de forma diferenciada, apesar de percebermos que em comum, elas possuem os mesmos ideais de formação (omnilateral, politécnica ou integral), mesma maneira de organizar os conteúdos (de forma interdisciplinar levando em conta a complexidade da prática educativa. Tal diversidade de sequências didáticas possíveis reforçam a percepção de que estas práticas devem ser experimentadas visando a transformação, pois

É condição para o desenvolvimento de práticas pedagógicas integradoras que os sujeitos de ensino, principalmente, e da aprendizagem revelem uma atitude 
humana transformadora que se materialize no seu compromisso político com os trabalhadores e com a sociedade dos trabalhadores, até porque as práticas educativas não se constituem na escola, tampouco tem implicações que se encerram nela (ARAUJO; FRIGOTO, 2015, p. 4).

Os autores complementam que a integração também é um ato de vontade de docentes e gestores o qual depende também de condições concretas para a efetivação, tais como: ambiente, as realidades específicas e os sujeitos envolvidos.

Em relação às práticas integradoras, refletimos sobre a existência de algumas experiências exitosas de integração por meio de aulas interdisciplinares, projetos interdisciplinares, projeto integrador, projetos de extensão e de pesquisa, oficinas, aulas de campo, gincanas, feiras interdisciplinares, projetos utilizando a pesquisa como princípio educativo, projetos de integração através do uso das TICS, dentre outros.

Em relação aos projetos de extensão que estão prescritos na Lei no 11.892 de 29 de dezembro de 2008, art. 70, inciso IV traz, sobretudo, como objetivos dos Institutos Federais, 0 desenvolvimento de projetos de extensão conforme os princípios da Educação Profissional e Tecnológica em articulação com o mundo do trabalho e o desenvolvimento local e regional, além, claro de evidenciar a relação teoria/prática, condição esta, indispensável para o desenvolvimento do currículo integrado. De acordo com Bonfim e Silva (2014, p. 4)

Projetos de extensão são de grande relevância para formação de pessoas em qualquer área de atuação profissional, pois os mesmos buscam tanto mostrar à sociedade os conhecimentos adquiridos pelos alunos no ambiente educacional quanto fazer com que o aluno perceba a importância de verificar na prática o que aprendeu na teoria em sala de aula, sendo assim esses projetos excelentes ações de práticas integradoras.

Em relação aos projetos que utilizam a pesquisa como princípio educativo, como por exemplo, os projetos de iniciação científica que são comuns na formação profissional dos estudantes do EMI colaboram para a construção de um novo conhecimento, fruto de estudos e experiências com várias áreas do saber que corroboram para um saber complexo. Nesses projetos de pesquisas também fica claro, a presença dos princípios que norteiam o EMI. Segundo Fazenda, (2005, p. 88) "aprender a pesquisar, fazendo pesquisa, é próprio de uma educação interdisciplinar, que, deveria se iniciar desde a pré-escola".

Além do princípio educativo, a pesquisa traz consigo, o princípio pedagógico com vistas a inquietar o estudante no sentido da curiosidade em direção ao mundo que o cerca possibilitando ser protagonista na produção de conhecimentos. Neste sentido, a pesquisa é apontada nas diretrizes para a educação profissional técnica de nível médio como aquela que é compreendida como

[...] atitude de inquietação diante da realidade e quando despertada no Ensino Médio, contribui para que o sujeito possa, individual ou coletivamente, formular questões de investigação e buscar respostas em um processo autônomo de (re) construção de conhecimentos (BRASIL, 2011, p. 22).

Nos Institutos Federais, a pesquisa é uma das bases sobre a qual se apoio o currículo integrado, juntamente com o ensino e a extensão, ou seja, se fundamenta no tripé 
(ensino/pesquisa/extensão). Os projetos de iniciação científica são desenvolvidos com alunos e professores em que o professor é um mediador no processo de construção do conhecimento junto com os estudantes. Estas experiências se evidenciam como uma prática educativa integradora e emancipadora à medida que desperta nos sujeitos, curiosidade, criatividade e coparticipação na construção do conhecimento, além do senso crítico que partindo de seus conhecimentos prévios e em contato com o conhecimento científico sistematizado os possibilitam à descoberta do "novo".

A partir da pesquisa como princípios educativos e pedagógico na formação integrada do estudante, buscam-se soluções para dificuldades postas pelas realidades sociais complexas e heterogêneas. Dessa forma, quando a pesquisa é associada aos projetos contextualizados com a comunidade na qual está inserida trazendo soluções para os problemas, este processo de pesquisa ganha contornos de uma amplitude social capaz de desenvolver em quem dele participa, valores e contribui significativamente para a formação integral.

De acordo com Grümm, Vieira e Brito (2014), por meio de um projeto de iniciação científica desenvolvido no campus Videira - Instituto Federal de Educação, Ciência e Tecnologia Catarinense - IFC, foi possível verificar que a experiência gerou entre os docentes envolvidos, reflexões acerca da integração entre o Ensino Médio Propedêutico e a Educação Profissional Técnica. Assim, percebeu-se a importância da interdisciplinaridade e da pesquisa como princípios educativo e pedagógico como um dos eixos vitais à formação humana.

Convém destacar que o projeto integrador também se constitui em uma ferramenta de produção e difusão do conhecimento escolar que tem ganhado espaço no âmbito dos IF, tanto no nível superior como no EMI. Tal amplitude espacial e de significância se tornou perceptível tanto aos docentes quanto aos estudantes em relação à essência da integralização curricular no EMI (GRÜMM; VIEIRA; BRITO,2014).

O Projeto Integrador é diferenciado se comparado às diversas outras práticas integradoras por ser um componente curricular que não traz, inicialmente, uma lista fixa de conteúdos, pois, nele, busca-se uma articulação entre os conhecimentos estudados nas disciplinas que integram cada período letivo na perspectiva da interdisciplinaridade. Os conteúdos, nessa perspectiva, são construídos ao longo do processo e deve depender da

[...]realidade a partir das necessidades de alunos e professores em estudar um determinado tema, que é gerador, para solucionar uma questão ou problemática do mundo do trabalho, do universo familiar, social, histórico e cultural (HENRIQUE; NASCIMENTO, 2015, p. 68).

As aulas interdisciplinares, projetos interdisciplinares e a disciplina projeto integrador e 0 uso das TICs são experiências realizadas pelos docentes com os alunos, muitas vezes, dentro da sala de aula que ressaltam no dia a dia da prática docente a integração por meio da interdisciplinaridade no decorrer das exposições dos professores ou projetos realizados pelos alunos. Por outro lado, as diversas outras formas de realizarem práticas integradoras nos mostram possibilidades de expandir as práticas integradoras para um âmbito que envolva a gestão e a colaboração entre diversos docentes na prática educativa em busca de uma proposta inovadora e integradora. 


\section{PRÁTICAS INTEGRADORAS NO EMI: ESTADO DO CONHECIMENTO}

Atualmente, a temática práticas integradoras têm demonstrado importância entre as práticas educativas em EPT, visto que sua vinculação com a proposta de ensino médio integrado vem promovendo, de certa forma, a integração curricular. Nesse caminho, o que se espera desta integração é mais que uma ação interdisciplinar, mas, sobretudo, uma prática que considere a formação integral do educando mediante os pressupostos agregados ao currículo integrado, sendo, portanto, a integração curricular no EMI, uma prática amparada em pressupostos críticos e políticos.

Dada a sua importância e atualidade nos debates e investigações científicas referentes à temática buscamos realizar um estado do conhecimento sobre o tema. Delineamos como objetivo geral desta pesquisa de natureza básica, investigar as principais práticas pedagógicas integradoras utilizadas no Ensino Médio Integrado a partir do estado do conhecimento utilizando-nos do banco de dados google acadêmico. Outra justificativa para realizar tal pesquisa deu-se por também acreditarmos que essas práticas integradoras sejam um recurso importante para a efetivação de um currículo realmente integrado e totalizador em busca da formação integral dos estudantes no citado contexto.

A nossa pesquisa que se configurou em um Estado de Conhecimento conforme preconiza (ROMANOVSKI, 2012), que implica uma investigação em apenas uma das plataformas, como por exemplo, utilizamos somente o google Acadêmico, mesmo tendo iniciado por um estado da arte. Neste sentido, ao fazermos alguns levantamentos iniciais por meio de um recorte temporal entre 2007 e 2017, averiguamos, inicialmente, por meio do uso do google acadêmico, o descritor "Práticas Educativas". Nesse descritor, surgiram 104.000 resultados, enquanto que ao se pesquisar com o descritor "Práticas Integradoras" apareceram 728 resultados, o que equivale a menos de $1 \%$ do termo práticas educativas quando pesquisado nesta plataforma de difusão do conhecimento científico. Com isto, percebemos que o universo das práticas integradoras ao se pesquisar com tal descritor tem um percentual baixíssimo o que nos leva a compreendermos, pelo menos, inicialmente e nesse contexto de pesquisa, que não existem muitos trabalhos acadêmicos nessa área.

Este resultado foi muito menor nos Catálogos de Teses e Dissertações da Capes que registrou 5498 resultados para o descritor "Práticas Educativas", e apenas, 11 resultados quando utilizamos o descritor "Práticas Integradoras". Por sua vez, também encontrou-se uma menor evidência de registros nos Periódicos da Capes, ou seja, 1925 resultados para o descritor "Práticas Educativas", e apenas, 8 resultados para o descritor "Práticas Integradoras". Percebemos assim, que embora existam muitos trabalhos sobre práticas educativas, poucos discorrem sobre práticas integradoras, isto é, mais um elemento de importância para continuarmos a investigar sobre esse descritor ou temática.

Ao se pesquisar os descritores "Práticas Integradoras" "Ensino Médio Integrado", obtivemos no Google Acadêmico, inicialmente, 72 resultados. Já no Periódicos Capes, obtivemos apenas 04 resultados. Somente no Catálogo de Teses e Dissertações da Capes este número curiosamente aumentou para 388 , gerando muito mais resultados do que quando se utilizava somente "Práticas Integradoras", e mesmo filtrando os resultados desta plataforma entre os anos de 2007 A 2017, ainda se registrou 294 teses/dissertações. 
Assim, considerando a quantidade de resultados, relevância e diversidade dos trabalhos conforme exposto de forma sintética, escolhemos o google acadêmico pela sua diversidade de artigos, tanto oriundos de eventos científico-acadêmicos quanto no tocante aos periódicos, principalmente, por acessarmos também nesta plataforma, dissertações e teses.

Com o uso dos mesmos descritores, "Práticas Integradoras" "Ensino Médio Integrado", com o filtro dos anos para o período de 2007 a 2017 e retirando as patentes e citações, obtivemos 61 resultados, os quais foram utilizados para nossa análise inicial mediante a leitura dos títulos e resumos, e, posteriormente, foram feitas leituras de introdução e capítulos importantes dos trabalhos previamente selecionados.

Diante da análise inicial dos 61 trabalhos relacionados às práticas integradoras no EMI, no tocante à natureza da pesquisa, verificamos que 24 trabalhos tratavam de pesquisa bibliográfica, documental ou exploratória, isto é, limitavam-se a explorar aspectos teóricos e conceituais, não sendo portanto objeto de análise do nosso estado do conhecimento, já que nos propomos a investigar práticas interdisciplinares as quais venham a contribuir para uma educação integral e que utiliza da categoria trabalho em seus pressupostos, ou seja, práticas que auxiliem na implementação do currículo integrado.

Dos demais, 14 foram excluídos por não falar de integração curricular, ou não ressaltarem as concepções do currículo integrado. Ainda encontramos nesses artigos alguns que tratavam de temáticas voltadas ao ensino superior e, deste modo, como a nossa proposta estava voltada ao Ensino Médio Integrado, também foram descartados do corpus de análise.

Foram retirados, ainda, 5 documentos, sendo 1 que tratava do Projeto Político Pedagógico - PPP; 1 que era resultado de anais de evento com todos os artigos de um evento científico; 2 livros, um com diversos artigos e outro com resultados de um projeto de atividade interdisciplinares/integradoras e 3 artigos que estavam repetidos. Por fim, localizaram-se 2 trabalhos que tratavam sobre formação continuada de docentes, que também não foram utilizados, visto que, o foco do levantamento foram as práticas educativas de natureza integradora que ocorrem no processo de ensino aprendizagem no EMI.

Por conseguinte, dos 61 trabalhos, apenas, 14 satisfizeram os critérios almejados para o nosso estudo. Isso reforça a necessidade de se realizar pesquisas e divulgar experiências exitosas que impliquem no estudo sobre práticas integradoras no EMI. Desses 14 trabalhos, 1 é caracterizado como tese, 2 são dissertações, 4 são artigos publicados em periódicos científicos e 7 são artigos publicados em anais de eventos conforme o quadro a seguir:

\begin{tabular}{|c|c|c|c|}
\hline \multicolumn{4}{|c|}{ Quadro Síntese dos trabalhos analisados no Google Acadêmico } \\
\hline $\begin{array}{l}\text { TÍTULO DO } \\
\text { TRABALHO }\end{array}$ & $\begin{array}{l}\text { OBJETIVO DO } \\
\text { TRABALHO }\end{array}$ & $\begin{array}{c}\text { TIPO DE TRABALHO/ } \\
\text { NATUREZA DA } \\
\text { PESQUISA } \\
\end{array}$ & $\begin{array}{c}\text { AUTORES/ LOCAL/ } \\
\text { ANO DE PUBLICAÇÃO } \\
\text { INSTITUIÇÃO VINCULADA }\end{array}$ \\
\hline $\begin{array}{l}\text { A Iniciação científica } \\
\text { no ensino médio } \\
\text { integrado como } \\
\text { possibilidade de uma } \\
\text { prática integradora: }\end{array}$ & $\begin{array}{l}\text { Relatar a } \\
\text { experiência } \\
\text { vivenciada em um } \\
\text { projeto de iniciação } \\
\text { científica intitulado }\end{array}$ & $\begin{array}{l}\text { Artigo } \\
\text { Pesquisa básica, } \\
\text { bibliográfica. }\end{array}$ & $\begin{array}{l}\text { Cristiane A. } \\
\text { F. Grümm. } \\
\text { Solange F. Vieira. } \\
\text { Liliane M. Brito. }\end{array}$ \\
\hline
\end{tabular}




\begin{tabular}{|c|c|c|c|}
\hline $\begin{array}{lr}\text { estudo de caso } \\
\text { através do resgate da } \\
\text { memória } & \text { da } \\
\text { vitivinicultura } & \text { em } \\
\text { videira, } & \text { Santa } \\
\text { Catarina. } & \end{array}$ & $\begin{array}{l}\text { "Resgate } \\
\text { Memória sobre a } \\
\text { produção da uva e } \\
\text { do vinho a partir da } \\
\text { década de } 1940 \text { no } \\
\text { município ranta } \\
\text { Videira, } \\
\text { Catarina". }\end{array}$ & & $\begin{array}{l}\text { HOLOS, v. 30, } 2014 . \\
\text { Instituto Federal Catarinense - } \\
\text { IFC }\end{array}$ \\
\hline $\begin{array}{l}\text { Concepções } \\
\text { Docentes: práticas } \\
\text { pedagógicas } \\
\text { integradoras e seus } \\
\text { desafios no IFRN. }\end{array}$ & $\begin{array}{lr}\text { Analisar } & \text { as } \\
\text { concepções } & \text { dos } \\
\text { docentes do EMI de } \\
\text { Informática } & \text { acerca } \\
\text { das práticas } \\
\text { pedagógicas } \\
\text { integradoras, } \\
\text { perspectiva } & \text { na } \\
\text { identificar se } & \text { elas } \\
\text { ocorrem } & \text { no } \\
\text { contexto } & \text { de } \\
\text { vivências } & \text { desses } \\
\text { educadores } & \\
\end{array}$ & $\begin{array}{l}\text { Artigo } \\
\text { Pesquisa básica, } \\
\text { bibliográfica } \\
\text { investigativa. }\end{array}$ & $\begin{array}{l}\text { Joaracy Lima de Paula. } \\
\text { Lanúzia Tércia F. de Sá. } \\
\text { Maria Adilina F. J. Andrade. } \\
\text { Revista Brasileira da Educação } \\
\text { Profissional e Tecnológica. V.1, } \\
\text { n.12. } 2017 . \\
\text { Instituto federal do Rio Grande } \\
\text { do Norte - IFRN }\end{array}$ \\
\hline $\begin{array}{lr}\text { A } & \text { integração } \\
\text { curricular } & \text { na } \\
\text { concepção } & \text { dos } \\
\text { docentes do } & \text { curso } \\
\text { técnico } & \text { em } \\
\text { agropecuária } & \\
\text { integrado ao ensino } \\
\text { médio. }\end{array}$ & $\begin{array}{l}\text { Identificar } \\
\text { elementos que } \\
\text { contribuíram na } \\
\text { construção de uma } \\
\text { organização } \\
\text { curricular de ensino } \\
\text { e de aprendizagens } \\
\text { fundamentada } \\
\text { numa concepção } \\
\text { integradora nas } \\
\text { práticas nos } \\
\text { docentes do curso } \\
\text { Técnico } \\
\text { Agropecuária } \\
\text { integrado ao Ensino } \\
\text { Médio do Instituto } \\
\text { Federal de Mato } \\
\text { Grosso - campus } \\
\text { Cáceres. }\end{array}$ & $\begin{array}{l}\text { Artigo } \\
\text { Pesquisa aplicada, } \\
\text { qualitativa. }\end{array}$ & $\begin{array}{l}\text { Denise Dalmás Rodrigues. } \\
\text { Maria Cristina Pansera de } \\
\text { Araújo. } \\
\text { Revista Brasileira da Educação } \\
\text { Profissional e Tecnológica, v. 1, } \\
\text { n. 12. 2017. } \\
\text { Universidade Regional do } \\
\text { Noroeste do Rio Grande do Sul. }\end{array}$ \\
\hline $\begin{array}{l}\text { Obesidade na } \\
\text { adolescência: a } \\
\text { interdisciplinaridade } \\
\text { como estratégia de } \\
\text { promoção da saúde. }\end{array}$ & $\begin{array}{lr}\text { Identificar } & \text { se } \\
\text { docentes de um } \\
\text { instituto federal } \\
\text { atuam na } \\
\text { perspectiva } \\
\text { trabalho do } \\
\text { interdisciplinar, } \\
\text { contribuindo para a } \\
\text { promoção da saúde }\end{array}$ & $\begin{array}{l}\text { Artigo } \\
\text { Pesquisa aplicada, } \\
\text { qualitativa, } \\
\text { descritiva, do tipo } \\
\text { estudo de caso. }\end{array}$ & $\begin{array}{l}\text { Edison Marcos B. Filho. } \\
\text { Geilsa Soraia Cavalcanti Valente. } \\
\text { Pensar a Prática, v. 20, n. } 4 . \\
2017 . \\
\text { Instituto Federal Fluminense- } \\
\text { IFF. } \\
\text { Universidade }\end{array}$ \\
\hline
\end{tabular}




\begin{tabular}{|c|c|c|c|}
\hline & $\begin{array}{l}\text { e a prevenção da } \\
\text { obesidade } \\
\text { escolares. }\end{array}$ & & Fluminense. \\
\hline $\begin{array}{l}\text { Projeto INCUTEC: uma } \\
\text { experiência de prática } \\
\text { integradora para o } \\
\text { Curso Técnico de } \\
\text { Administração do } \\
\text { IFMA Campus } \\
\text { Buriticupu. }\end{array}$ & 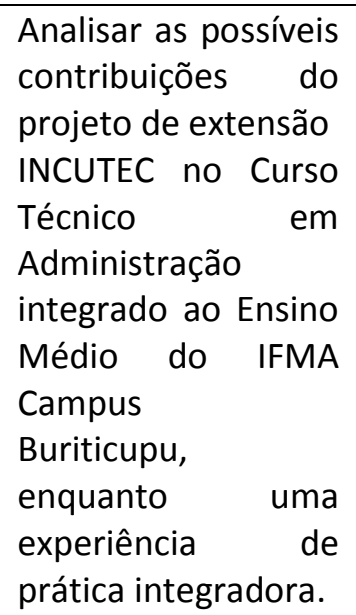 & $\begin{array}{l}\text { Artigo } \\
\text { Pesquisa qualitativa, } \\
\text { bibliográfica, } \\
\text { Documental e de } \\
\text { campo. }\end{array}$ & $\begin{array}{l}\text { Cristiani Hembecker Bomfim. } \\
\text { Camila Mara R. Silva. } \\
\text { HOLOS, v. 2, } 2014 \\
\text { Instituto Federal do Maranhão - } \\
\text { IFMA. }\end{array}$ \\
\hline $\begin{array}{l}\text { Modelagem e } \\
\text { educação profissional: } \\
\text { possíveis relações em } \\
\text { uma abordagem } \\
\text { pedagógica para } \\
\text { soluções químicas no } \\
\text { ensino médio } \\
\text { integrado ao técnico } \\
\text { em informática. }\end{array}$ & $\begin{array}{l}\text { Apresentar os } \\
\text { resultados de uma } \\
\text { pesquisa qualitativa, } \\
\text { que analisa o } \\
\text { desenvolvimento de } \\
\text { atividades } \\
\text { integradoras } \\
\text { fundamentadas em } \\
\text { modelagem como } \\
\text { estratégia didática } \\
\text { para o ensino médio } \\
\text { integrado ao técnico } \\
\text { em informática. }\end{array}$ & $\begin{array}{l}\text { Artigo } \\
\text { Pesquisa aplicada, } \\
\text { qualitativa. }\end{array}$ & $\begin{array}{l}\text { Lucas Pereira. } \\
\text { Gilson Saturnino. } \\
\text { Alexandre Geraldo Viana Faria. } \\
\text { Colóquio Nacional-A produção } \\
\text { do conhecimento em Educação } \\
\text { Profissional, } 2015 . \\
\text { Instituto Federal Mato Grosso } \\
\text { do Sul - IFMS. }\end{array}$ \\
\hline $\begin{array}{l}\text { Práticas pedagógicas } \\
\text { integradoras: } \\
\text { concepções e desafios } \\
\text { dos docentes no } \\
\text { contexto de vivência } \\
\text { do curso de } \\
\text { informática do IFRN. }\end{array}$ & $\begin{array}{lr}\text { Analisar } & \text { as } \\
\text { concepções } & \text { dos } \\
\text { docentes do EMI de } \\
\text { Informática } & \text { acerca } \\
\text { das práticas } \\
\text { pedagógicas } \\
\text { integradoras, } \\
\text { perspectiva } & \text { na } \\
\text { identificar se } & \text { elas } \\
\text { ocorrem } & \text { no } \\
\text { contexto } & \text { de } \\
\text { vivências } & \text { desses } \\
\text { educadores } & \end{array}$ & $\begin{array}{l}\text { Artigo } \\
\text { Pesquisa básica, } \\
\text { bibliográfica } \\
\text { investigativa. }\end{array}$ & $\begin{array}{l}\text { Joaracy Lima de Paula. } \\
\text { Lanúzia Tercia Freire de Sá. } \\
\text { Maria Adilina Freire Jerônimo de } \\
\text { Andrade. } \\
\text { Congresso Nacional em } \\
\text { Educação-CONEDU- } 2015 \text {. } \\
\text { Instituto Federal do Rio Grande } \\
\text { do Norte-IFRN. }\end{array}$ \\
\hline $\begin{array}{l}\text { Da integração } \\
\text { desejada às práticas } \\
\text { pedagógicas } \\
\text { fragmentadas. }\end{array}$ & $\begin{array}{l}\text { Compreender } r \\
\text { relação entre essas } \\
\text { práticas } \\
\text { pedagógicas } \\
\text { integradoras } \\
\text { promovidas pelo } \\
\text { IFPB e as estratégias }\end{array}$ & $\begin{array}{l}\text { Artigo } \\
\text { Pesquisa básica, } \\
\text { bibliográfica. }\end{array}$ & $\begin{array}{l}\text { Colóquio Nacional - A produção } \\
\text { do conhecimento em Educação } \\
\text { Profissional, } 2015 .\end{array}$ \\
\hline
\end{tabular}




\begin{tabular}{|c|c|c|c|}
\hline & $\begin{array}{l}\text { de integração } \\
\text { contidas nos PPCs. }\end{array}$ & & $\begin{array}{l}\text { Universidade Federal do Rio } \\
\text { grande do Norte-UFRN }\end{array}$ \\
\hline $\begin{array}{l}\text { Pesquisa como } \\
\text { princípio educativo: } \\
\text { uma proposta de } \\
\text { prática pedagógica } \\
\text { integradora. }\end{array}$ & $\begin{array}{l}\text { Apresentar } \\
\text { reflexões sobre a } \\
\text { utilização da } \\
\text { pesquisa como } \\
\text { princípio educativo, } \\
\text { numa perspectiva } \\
\text { de promoção de } \\
\text { ações integradoras } \\
\text { principalmente no } \\
\text { que tange à } \\
\text { indissociabilidade } \\
\text { entre ensino e } \\
\text { pesquisa. }\end{array}$ & Pesquisa Básica & $\begin{array}{l}\text { Roberta Silva L. Dalarme. } \\
\text { Colóquio Nacional - A produção } \\
\text { do conhecimento em Educação } \\
\text { Profissional, } 2015 . \\
\text { Instituto Federal Fluminense - } \\
\text { IFF }\end{array}$ \\
\hline $\begin{array}{l}\text { Formação docente } \\
\text { para o uso das TIC no } \\
\text { contexto da educação } \\
\text { profissional: por um } \\
\text { diálogo com } \quad \text { a } \\
\text { formação humana } \\
\text { integral. }\end{array}$ & $\begin{array}{l}\text { Discutir a formação } \\
\text { de professores para } \\
\text { atuação no âmbito } \\
\text { da } \quad \text { Educação } \\
\text { Profissional(EP) com } \\
\text { o uso das TIC na } \\
\text { perspectiva } \\
\text { formação humana } \\
\text { integral. }\end{array}$ & $\begin{array}{l}\text { Artigo } \\
\text { Pesquisa básica, } \\
\text { qualitativa, } \\
\text { bibliográfica. }\end{array}$ & $\begin{array}{l}\text { Dediane Cristina de Sá Mororó. } \\
\text { José Mateus do Nascimento. } \\
\text { Colóquio Nacional e Colóquio } \\
\text { Internacional -. A produção do } \\
\text { conhecimento em educação } \\
\text { profissional. } 2017 \text {. } \\
\text { Instituto Federal do Rio Grande } \\
\text { do Norte-IFRN. }\end{array}$ \\
\hline $\begin{array}{lr}\text { O desafio pedagógico } \\
\text { da política } & \text { de } \\
\text { integração no } & \text { centro } \\
\text { territorial } & \text { de } \\
\text { educação profissional } \\
\text { da região } \\
\text { metropolitana } \\
\text { Salvador/Bahia. }\end{array}$ & $\begin{array}{l}\text { Analisar os desafios } \\
\text { da construção de } \\
\text { uma política de } \\
\text { educação integral } \\
\text { para a classe } \\
\text { trabalhadora, no } \\
\text { contexto de } \\
\text { expansão da oferta, } \\
\text { na rede estadual de } \\
\text { ensino baiana. }\end{array}$ & $\begin{array}{l}\text { Artigo } \\
\text { Pesquisa } \\
\text { documental, } \\
\text { bibliográfica e de } \\
\text { campo }\end{array}$ & $\begin{array}{l}\text { Aline de Oliveira Costa de } \\
\text { Santos. Roberto da Cruz Melo. } \\
\text { Colóquio Nacional - A produção } \\
\text { do conhecimento em Educação } \\
\text { Profissional, } 2017 . \\
\text { Instituto Federal da Bahia - IFBA }\end{array}$ \\
\hline $\begin{array}{l}\text { Os desafios da } \\
\text { integração curricular } \\
\text { na gestão pedagógica } \\
\text { da Escola Estadual de } \\
\text { Educação Profissional } \\
\text { Elsa Maria Porto Costa } \\
\text { Lima no curso técnico } \\
\text { de hospedagem. }\end{array}$ & 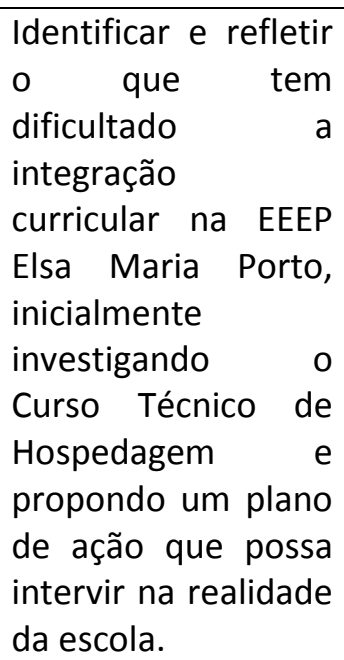 & $\begin{array}{l}\text { Dissertação } \\
\text { Pesquisa aplicada, do } \\
\text { tipo estudo de caso. }\end{array}$ & $\begin{array}{l}\text { Dulcimaria Portocarrero } \\
\text { Pinheiro. } \\
\text { Faculdade de Educação. } \\
\text { Universidade Federal de Juiz de } \\
\text { Fora -UFJF. 2016. }\end{array}$ \\
\hline
\end{tabular}




\begin{tabular}{|c|c|c|c|}
\hline $\begin{array}{l}\text { Geografia na } \\
\text { integração curricular: } \\
\text { vivências reflexivas no } \\
\text { Curso Técnico em } \\
\text { Eventos-IF } \\
\text { Farroupilha-São } \\
\text { Borja/RS. }\end{array}$ & $\begin{array}{l}\text { Compreender a } \\
\text { constituição do } \\
\text { ensino profissional, } \\
\text { dos fundamentos do } \\
\text { currículo integrado } \\
\text { e as possibilidades } \\
\text { de integração } \\
\text { curricular, a partir } \\
\text { de uma disciplina - } \\
\text { Geografia. }\end{array}$ & Dissertação & $\begin{array}{l}\text { Emersom Ciocheta Roballo. } \\
\text { Universidade Regional do } \\
\text { Noroeste do Estado do Rio } \\
\text { Grande do Sul-UNIJUÍ. } 2014 .\end{array}$ \\
\hline $\begin{array}{l}\text { Sobre o processo de } \\
\text { construção de um } \\
\text { "inédito viável": } \\
\text { sentidos do currículo } \\
\text { integrado } \\
\begin{array}{l}\text { campus de JPPB } \\
\text { Pessoa (2004 - 2014) }\end{array}\end{array}$ & & Tese & Ana Lúcia Ferreira de Queiroga \\
\hline
\end{tabular}

Quadro 1 - Síntese dos trabalhos analisados no Google Acadêmico. Fonte: Autoria própria.

Continuando com o estado do conhecimento, podemos afirmar que a maioria dos trabalhos foi realizado por doutores, mestres ou mestrandos, sendo que só fora encontrado 1 autor com título de especialização e em alguns casos, tiveram autores que não foram encontradas as suas formações acadêmicas. Um fato curioso sobre as autorias das pesquisas diz respeito aos seguintes dados: das 14 produções analisadas, 13 possuíam pelo menos, 1 servidor, dos Institutos Federais, sendo que 8 foram produzidos, exclusivamente, por servidores (professores ou técnico- administrativos); 5 produções possuíam servidores tanto dos IF quanto de outras instituições, e apenas 1 produção possuía somente autores que não atuam nos IF. Isso demonstra que grande parte da produção acerca das práticas integradoras no Ensino Médio Integrado vem sendo realizada por servidores ou alunos de mestrado dos IF. Quanto às instituições envolvidas, nos textos em estudo, encontramos: Instituto Federal de Educação, Ciência e Tecnologia do Rio Grande do Norte - IFRN; Instituto Federal de Educação, Ciência e Tecnologia do Maranhão - IFMA; Instituto Federal de Educação, Ciência e Tecnologia do Mato Grosso - IFMT, Instituto Federal de Educação, Ciência e Tecnologia Fluminense - IFF; Instituto Federal de Educação, Ciência e Tecnologia da Bahia - IFBA, Instituto Federal de Educação, Ciência e Tecnologia Catarinense - IFC e Universidade Regional do Noroeste do Estado do Rio Grande do Sul - UNIJUI.

Quanto aos autores utilizados, os mais citados são Ciavatta, M., Ramos, M., Frigotto G., Saviani, D., reconhecidos no campo da educação profissional no páis e Fazenda; I.C., nos conteúdos relacionados à interdisciplinaridade. Também havia bastante referências de Demo, P.; Freire, P.; Kuenzer, A. Z. e Libâneo, A. C. que é o mais utilizado nas fundamentações das metodologias, além de Milton, S. que, embora não tão conhecido, já se tornou uma referência utilizada em muitos trabalhos. Há uma quantidade razoável de referências de Lopes, A.C.; Mendonça, P. C. C.; Moura, D. H.; Pinheiro, R. e Matos, R. A. 
No tocante aos documentos legais institucionais, cabe salientar que a Lei 9.394/96 que estabelece as Diretrizes e Bases da Educação e a Lei 11.892/08 que institui a Rede Federal de Educação Profissional e cria os Institutos Federais foram as mais utilizadas nos textos analisados.

Dentre os 14 trabalhos selecionados, os projetos interdisciplinares como estratégia de integração foram citados 5 vezes, ou seja, 35\%. 2 artigos, isto é, 14\% das produções analisadas traziam o projeto integrador como atividades consideradas importantes para os docentes na integração das disciplinas. Há também 1 produção, ou seja, 7\% que tratava a respeito do projeto de extensão como prática integradora das disciplinas técnicas e propedêuticas. Outros 2 artigos (14\%) que relatam as experiências de uma prática integradora através da iniciação científica, utilizando-se da pesquisa como princípio educativo na perspectiva de promoção de ações integradoras que contribuem para a formação integrada dos estudantes.

Apontamos ainda 2 (14\%) dos trabalhos que apresentaram resultados de pesquisas sobre o uso das Tecnologias da Informação e Comunicação - TICS no contexto da Educação profissional, sendo que um deles apresenta a necessidade de um processo formativo de docentes para o uso das TICs nas práticas da EPT, considerando seu impacto no mundo do trabalho, e o outro traz resultados de uma pesquisa utilizando o uso das TICs com a disciplina de química como forma de contribuir para a formação geral e específica dos alunos.

Há ainda 1 dissertação equivalente a (7\%) que aborda práticas interdisciplinares no EMI e as possibilidades de integração curricular, integração entre disciplinas propedêuticas e técnicas partindo da disciplina de Geografia. A tese de doutorado que equivale a (7\%) propõe-se a investigar o que impede a implementação do currículo integrado no Instituto Federal de Educação, Ciência e Tecnologia da Paraíba - IFPB, evidenciando que apesar do conjunto de atividades pedagógicas com vistas à integração curricular, ainda são muitos os empecilhos para efetivação do currículo integrado, por exemplo: a falta de clareza no conceito de integração, a estrutura organizacional e falta de formação docente para a EPT. Também foram abordadas outras práticas integradoras no EMI tais como: aula de campo, oficina, gincana, reuniões pedagógicas e seminário interdisciplinar, conforme quadro a seguir:

\begin{tabular}{|c|c|c|}
\hline Práticas pedagógicas encontradas & Quantidade & Percentual \\
\hline Projetos Interdisciplinares & 05 & $35 \%$ \\
\hline Projeto Integrador & 02 & $14 \%$ \\
\hline Projeto de Extensão & 01 & $07 \%$ \\
\hline Prática integradora por meio da iniciação científica & 02 & $14 \%$ \\
\hline Uso das TIC na EPT & 02 & $14 \%$ \\
\hline Praticas Interdisciplinares no EMI & 01 & $07 \%$ \\
\hline
\end{tabular}

Quadro 2 - Principais práticas integradoras encontradas nas pesquisas. Fonte: Autoria própria.

Os objetivos da maioria das pesquisas consiste em investigar práticas que contribuam com a aproximação da teoria e prática, a integração entre disciplinas técnicas e de formação geral e 
que vise a formação integrada dos alunos, além de apresentar relatos de experiências de implantação do EMI ou de projetos desenvolvidos em prol da integração e resultados de práticas exitosas naquele contexto.

Os temas dos trabalhos são relevantes e podem incentivar a adoção de tais práticas em outras instituições/realidades, no entanto, ainda são poucas as pesquisas nesse âmbito. 0 Decreto no 5.154 /2004 foi aprovado há 14 anos e, embora, tenhamos dados passos significativos rumo ao rompimento com a dualidade educacional e a efetivação do currículo integrado, ainda nos faltam ações concretas e contínuas. As pesquisas que demostraram práticas de integração no EMI devem ser mais exploradas por pesquisadores em outras investigações científicas.

\section{CONSIDERAÇÕES FINAIS}

Este estudo teve, como temática central, as práticas integradoras que emergem no âmbito do Ensino Médio Integrado. Tais práticas integradoras surgem como desafios à integração entre as diferentes disciplinas e áreas do conhecimento na formação integrada dos estudantes do EMI. A nossa análise mostra que a maioria dessas práticas integradoras está situada em projetos interdisciplinares como iniciativas pontuais de integração. E, por vezes, o projeto integrador e demais práticas apontadas no estudo surgem como atividades promissoras de fortalecimento da concepção de currículo integrado e da formação integrada dos referidos estudantes naquele contexto educacional.

Compreendemos que as práticas integradoras explicitadas nesse estudo buscam ressignificar estratégias de ensino-aprendizagem com o intuito da promoção de um ensino pautado na perspectiva de integração entre disciplinas técnicas e propedêuticas, ou seja, em consonância com as diretrizes do EMI para uma formação, não apenas técnica, mas, sobretudo, com ampla capacidade de desenvolvimento intelectual de forma mais humanizada, complexa, crítica e criativa.

Muitos são os desafios que se impõem aos professores e à sua prática docente no universo da sala de aula e no seu fazer pedagógico e situar práticas pedagógicas integradoras tem sido um desafio que implica a materialização de um novo paradigma de pensamento e de ações, que possam culminar em uma prática socializadora do conhecimento.

Muitas são as possibilidades de estratégias para a realização das práticas integradoras na perspectiva do EMI, no entanto, percebemos que articular práticas que integrem uma formação humana em sua totalidade não é tarefa fácil. Isso nos é demonstrado, a partir, dos poucos trabalhos que evidenciam tais práticas conforme pode ser refletido neste artigo. É salutar, pois, que nos empenhemos em desmitificar a nossa teoria e a nossa prática, para assim, encontrarmos possíveis caminhos para um saber construído no diálogo entre os envolvidos nos processos educativos.

Percebemos através deste trabalho, a iminente necessidade de estudos sobre a incidência de práticas integradoras nas instituições de ensino que ofertam o EMI, como por exemplo, os IF, as Escolas Agrícolas vinculadas às Universidades Federais, as escolas estaduais que ofertam a educação profissional no ensino médio. Por fim, poucas são as pesquisas que visam investigar ou demostrar como essas práticas acontecem, quais suas contribuições no tocante a formação integrada do estudante, e, necessariamente, que demonstre quais são os propósitos desejados e 
como os professores estão desenvolvendo tais práticas integradoras com o fito de viabilizar um processo de ensino-aprendizagem que culmine na transformação dos sujeitos aprendizes.

\section{REFERÊNCIAS}

BRASIL. MEC/SETEC. CNE/CEB (2012). Diretrizes Curriculares Nacionais para a Educação Profissional Técnica de Nível Médio.

. CNE/CEB (2011). Diretrizes Curriculares Nacionais para o Ensino Médio. Brasília, DF. (2004). Decreto no 5.154, de 23 de julho de 2004. Regulamenta o § 20 do art. 36 e os arts. 39 a 41 da Lei no 9.394, de 20 de dezembro de 1996, que estabelece as diretrizes e bases da Educação Nacional. Brasília.

. (2008). Lei n. 11.892 de 29 de dezembro de 2008. Lei que institui a Rede Federal de Educação Profissional, Científica e Tecnológica, cria os Institutos Federais de Educação, Ciência e Tecnologia, e dá outras providências. Brasília, DF.

BONFIM, Cristiani Hembecker; SILVA, Camila Mara Rodrigues (2014). Projeto INCUTEC: uma experiência de prática integradora para o Curso Técnico de Administração do IFMA Campus Buriticupu. HOLOS, 2(30),75-86.

LIMA ARAUJO, Ronaldo Marcos de; FRIGOTTO, Gaudêncio (2015). Práticas pedagógicas e ensino integrado. Revista Educação em Questão, 52(38),61-80.

FAZENDA, Ivani Catarina Arantes (2005). Interdisciplinaridade: história, teoria e pesquisa. Papirus editora.

LIBÂNEO, José Carlos (2013). Didática. - 2ª ed..São Paulo: Cortez.

GRÜMM, Cristiane Aparecida Fontana; VIEIRA, Solange Francieli; BRITO, L. M (2014). A iniciação científica no ensino médio integrado como possibilidade de uma prática integradora: estudo de caso através do resgate da memória da vitivinicultura em Videira, Santa Catarina. HOLOS, 30(2), 143-153.

HENRIQUE, Ana Lúcia Sarmento; NASCIMENTO, José Mateus (2015). Sobre práticas integradoras: um estudo de ações pedagógicas na educação básica. HOLOS, 4(31) 63-76.

RAMOS, Marise N (2005). Possibilidades e Desafios na Organização do Currículo Integrado. In: RAMOS, Marise N. (Org.); FRIGOTTO, Gaudêncio (Org.); CIAVATTA, Maria (Org.) Ensino Médio Integrado: Concepção e Contradições. 1. ed. São Paulo: Cortez.

ROMANOWSKI, J. P. Apontamentos em pesquisas sobre formação de professores: contribuições para o debate. Revista Diálogo Educacional (PUCPR), v.37, p. 905 - 924, 2012.

SACRISTÁN, Gimeno J.; GÓMEZ, Al Pérez (2009). Compreender e transformar o ensino. 4a ed. Artmed Editora.

ZABALA, Antoni (1998). A prática educativa: como ensinar. Penso Editora. 